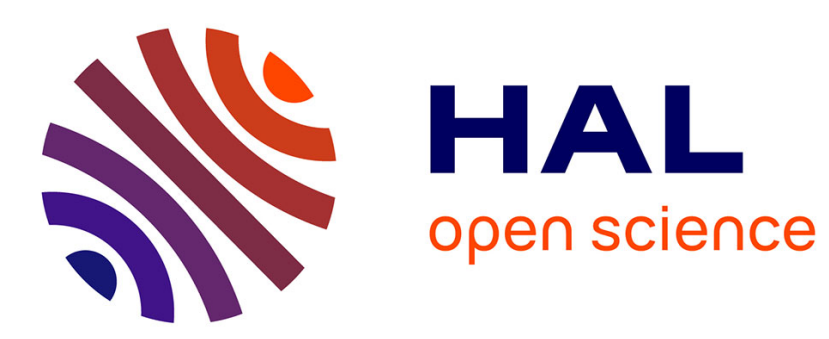

\title{
ANTECEDENTS OF SUBJECTIVE AGE BIASES AMONG SENIOR WOMEN
}

\author{
Denis Guiot
}

\section{To cite this version:}

Denis Guiot. ANTECEDENTS OF SUBJECTIVE AGE BIASES AMONG SENIOR WOMEN. Psychology \& Marketing, 2001, 18 (10), pp.1049. halshs-00169445

\section{HAL Id: halshs-00169445 \\ https://shs.hal.science/halshs-00169445}

Submitted on 4 Sep 2007

HAL is a multi-disciplinary open access archive for the deposit and dissemination of scientific research documents, whether they are published or not. The documents may come from teaching and research institutions in France or abroad, or from public or private research centers.
L'archive ouverte pluridisciplinaire HAL, est destinée au dépôt et à la diffusion de documents scientifiques de niveau recherche, publiés ou non, émanant des établissements d'enseignement et de recherche français ou étrangers, des laboratoires publics ou privés. 


\title{
ANTECEDENTS OF SUBJECTIVE AGE BIASES AMONG SENIOR WOMEN
}

\author{
Denis Guiot \\ Maître de Conférences \\ LARGO Research Center, University of Angers \\ France
}




\section{ANTECEDENTS OF SUBJECTIVE AGE BIASES AMONG SENIOR WOMEN}

Abstract

From a conceptual framework based on developmental psychology and mechanisms of social comparison, this research proposes testing an explanatory model of the trend to see oneself as younger which is characteristic of seniors. The identification of antecedent variables of this tendency suggests a new approach to segmenting the feminine over fifties market in France. 


\section{INTRODUCTION}

The concept of subjective age was introduced in marketing to palliate the limits of chronological, or real age as a variable for segmenting seniors' markets. A substantial body of research on people over 50 (Wolfe, 1992; Moschis, 1994) has emphasized how little pertinence chronological age has. As an alternative, research suggests studying the influence of the subjective dimension of age which complements chronological age insofar as it characterizes the way in which a person experiences his own age. Subjective age was conceptualized as a manifestation of a self-image defense and was initially defined as "the individual's selfperception in terms of reference age groups." (Blau, 1956). To this end, most studies have shown that seniors have a tendency to see themselves as 10 to 15 years younger than they actually are. Yet very few investigations have been carried out to reveal the cause of these differences. There are several reasons for the restricted amount of research in this field.

First it should be stressed that there are no formal theoretical frameworks likely to enable the identification of antecedent variables of discrepancies between the chronological age and subjective age of seniors. In addition, apart from Wilkes model (1992), most links established with subjective age are bivariable and do not always take into account the effect of chronological age on these relations. Henderson, Goldsmith and Flynn (1995) reported that when chronological age is controlled, correlations with certain assumed demographic causes are no longer significant. Their work confirms the contradictory nature of results that have been published. The presumed causes seem to be correlates rather than real antecedents (Barak and Stern, 1986; Barak, 1987; Barak, 1998). If these observations are correct, it is necessary to look deeper into the identification of antecedent variables of this characteristic in seniors to see themselves as younger than their chronological age (youthful bias). In particular, research should be orientated towards discovering psychographic determinants (Chua, Cote and Leong, 1990; Hubley and Hultsch, 1994). This research should help to profile the process leading to these discrepancies. Thereby, needs that are under or not satisfied are likely to be identified.

After having developed a conceptual framework based on developmental psychology and the mechanisms of social comparison, we propose testing an explanatory model of the formation of 
this youthful bias in seniors. Later, by using the antecedents that have been identified for this trend, we propose a new approach to segmenting the senior female population.

\section{THE CONCEPTUAL FRAMEWORK OF THE RESEARCH}

Barak and Schiffman introduced the concept of subjective age in marketing in 1981, using hypotheses drawn from the cognitive theory of aging (Thomas, 1970). Different frameworks proposed by research led to the development of many measuring tools, probably as a consequence of the variety of approaches developed in gerontology and in developmental psychology (Van Auken and Barry, 1995). In the broadest sense, subjective age includes all cognitive and affective representations associated with age and with aging (Gana, 1995). Consumer behavior defines this in the narrowest sense as cognitive age, or self-perceived age, a component of self-concept.

Barak and Schiffman (1981) proposed a scale for cognitive age. This scale and the gap between chronological and cognitive age, can be used interchangeably to measure the same concept (Chua, Cote and Leong, 1990; Hubley and Hultsch, 1994; Johnson, 1995). The first

measurement lets us characterize the age to which individuals identify, and the second determines the direction and the size of the subjective age bias, the tendency to see oneself as either older or younger than one's chronological age (Steitz and McClary, 1985, 1988; Staats, 1996). This ambiguity has managerial and methodological repercussions: should the researcher identify the causes of cognitive age or the subjective age bias? The second approach was preferred for several reasons. Conceptually speaking, the self-discrepancy theory (Higgins, 1987) states that the difference between the objective self and the subjective self influence behavior more than any single element. Moschis (1992) concurs, suggesting that the gap between chronological and cognitive age influences the consumption of products destined to defend self-image because of the self-consistency motive. Practically speaking, cognitive age taken alone does not allow us to identify the presence or absence of an eventual gap between chronological and cognitive age. The correlation coefficients between these two variables, observed in female populations between 20 and 90 years of age, are between .75 and .90 (Barak 
and Stern, 1985; Henderson, Goldsmith, and Flynn, 1995). These coefficients let us suppose a lack of discriminant validity of cognitive age because of the strong relationship. One explanation is the higher proportion of individuals between 20 and 50 years of age with no age bias, for whom cognitive age is the same as chronological age. (Barak and Gould, 1985; Henderson, Goldsmith, and Flynn, 1995). This proportion seems much lower for senior females the majority of whom reveal a youthful bias (Staats, 1996).

Heckhausen and Krueger (1993) claim that normative conceptions of human development cause the gap between chronological and subjective age. These normative conceptions are temporal references that allow an individual to evaluate his or her position in terms of physical and social development, and future prospects with respect to life cycle. They include two types of interdependent cognition: those linked to the self and those linked to others. For selfevaluation, these norms use comparison mechanisms (Festinger, 1954) and reference groups are therefore extremely important. A considerable amount of research has shown that age constitutes an identifiable reference group. A person belongs or wants to belong to an age group, is affected by a group or sees the group as an ideal insofar as it is a means of social categorization (Montepare and Zebrowitz, 1998). Age is also the subject of labeling due to associated social roles and stereotypes (Tepper, 1994 ; Alaphilippe et Bailly, 1997).

Subjective age bias concepts fall into the life-span theory of control developed by Heckhausen and Shulz (1995). Age biases are defined as the manifestation of a compensatory regulation process of self elements linked to age. These control mechanisms are particularly important at stages in life when self-image is being questioned frequently (Erikson, 1963; Neugarten, 1968, 1979). The latter seem more frequent for women than for men according to the double-standard theory (Sontag, 1975; Hagestad et Neugarten, 1985; Hansson, 1989).

These reasons led us to be more interested in senior females in this research.

Through certain characteristic, repeated events in life, they become conscious of aging which inevitably happens. Heckhausen and Shulz underlined the importance of social comparison mechanisms in the regulation process. This process results in a confrontation between an individual's questioning of his identity and his idea of others' views of normal human 
development. From this confrontation he sets developmental aspirations. These are feelings, expectations or beliefs about his own physical, psychological and social development. Depending on the degree of difference between these elements and evocations associated with chronological age, a difference between chronological age and subjective age is likely to be revealed. If there is no difference in these elements, individuals tend to show no age bias.

Developmental aspirations can be considered as one of the main factors determining subjective age biases. Becoming aware of aging activates several defense mechanisms of self-image which simultaneously affect the formation of developmental aspirations. Two of them may be distinguished in seniors.

The first, manifestation of a process of social comparison, reflects the desire to maintain social roles perceived as characteristic of younger people (aspiration to be younger). By their development, individuals exceeding 50 occupy or have occupied roles that they consider enhancing. Thus they wish to remain in these roles for as long as possible. Seniors are very unlikely to have a tendency in the opposite direction (aspiration to be older) in the aim of selfimprovment. This is due to negative stereotypes associated with aging.

The second corresponds to a desire to be detached from chronological age: the feeling of remaining young. Exposed by the theory of continuity (Atchley, 1993, 1996), this can be defined for seniors as the feeling of conserving the same aptitudes and physical, mental or social capacities as when the person was younger. The discrepancy between chronological age and subjective age will be bigger when this feeling is stronger. In general, the stronger the developmental aspirations the more pronounced the discrepancy between the two types of age. We have formulated the following hypotheses:

H1 : FOR SENIOR WOMEN, THE STRONGER THE ASPIRATION TO BE YOUNGER THEN THE BIGGER THE DISCREPANCY BETWEEN CHRONOLOGICAL AND SUBJECTIVE AGE.

H2 : FOR SENIOR WOMEN, THE STRONGER THE FEELING OF REMAINING YOUNG THEN THE BIGGER THE DISCREPANCY BETWEEN CHRONOLOGICAL AND SUBJECTIVE AGE.

Recently published research in developmental psychology and consumer behavior suggest that when there is negative self-esteem, the defense process and the process of improved self-image 
are more likely to be activated (Brandtstadter, 1989). Physical factors seem to be affected first because they are visible. By their very nature, the formation of developmental aspirations should be influenced by variables of appearance.

In Western societies, cultural norms dictate the importance of being physically attractive and in particular, thin. This preoccupation evokes agility. It symbolizes a young appearance for seniors (Barak and Stern, 1985). All these factors affect self-assessment due to a stereotype of physical attractiveness. It is a process which consists of attributing favorable characteristics or types of personality to physically attractive people and unfavorable characteristics to unattractive people. The existence of this stereotype was shown by a meta-analysis based on the implicit theory of personality (Eagly et al., 1991). Most studies have shown that a positive relation exists between perceived physical attractiveness and self-esteem (Krantz, Friedberg and Andrews, 1985; Rozin et Fallon, 1988; Franzoi, 1995).

Moreover, the same research theme suggests that double stereotypes of aging and physical attractiveness associate youth and beauty (Vacker and Key, 1993). For this reason, seniors whose perceived level of attractiveness is high should have a stronger feeling of remaining youthful.

The following hypothesis may be made:

H3 : FOR FEMALE SENIORS THE MORE THEY ARE SATISFIED WITH THEIR PHYSICAL APPEARANCE THEN THE HIGHER THEIR SELF-ESTEEM

H4 : FOR FEMALE SENIORS, THE MORE THEY ARE SATISFIED WITH THEIR PHYSICAL APPEARANCE THEN THE STRONGER THEIR FEELING OF REMAINING YOUNG

Several authors have shown the impact of standards of appearance in the context of social comparison. They play the role of indicators or guides of the potential of improving physical features (Vacker et Key, 1993). They particularly influence persons who place more importance on physical features as these people are more inclined to improve their image in situations of social comparison (Richins, 1991). 
When seniors are specifically targeted (e.g. anti-wrinkle creams), standards of beauty tend to be increasingly projected by older models who look young or whose apparent age is under fifty (Engel, Blackwell and Miniard, 1995).

With the aim of self-improvement, we have assumed there is a relation between the concern for physical appearance and the desire to do something to remain young amongst seniors.

H5 : FOR SENIOR WOMEN, THE GREATER THE CONCERN FOR PHYSICAL APPEARANCE THEN THE HIGHER THE ASPIRATION TO BE YOUNGER

Another important factor stems from the nature of seniors' stage in life. Seniors are more or less preoccupied with the physical and/or social consequences of their advanced age. Those persons that are very frightened of aging, are more likely to take steps to preserve and conserve attributes that are typical of younger people (physical appearance, social roles etc.). We have called this compensatory desire "aspiration to be younger". We shall study the interactions of these variables on the formation of subjective age biases in seniors.

Self-esteem must exercise an indirect influence on seniors. People over fifty are conscious of their aging. The first physical signs of this are likely to appear as early as twenty years old but are only perceptible much later. Observing such signs may provoke self-image defense reactions. The aspiration to be younger in seniors has been defined as one of these reactions. This desire should only be activated by negative self-esteem if the individual is frightened of aging. Consequently, the link between self-esteem and the aspiration to be younger should depend on the mediating role of the fear of aging.

We have made the following hypothesis:

H6 : FOR SENIOR WOMEN, THE FEAR OF AGING IS A MEDIATING VARIABLE OF THE RELATION BETWEEN SELF-ESTEEM AND THE ASPIRATION TO BE YOUNGER.

In the above argument, the presence of a mediating variable leads us to question the relationship between, on the one hand, self-esteem and fear of aging, and on the other hand, the 
fear of aging and the aspiration to be younger. The second link must be stronger for persons who have the feeling they can alter their physical and/or social appearance. Heckhausen \& Krueger (1993) studied defense mechanisms of self-image in seniors. They underlined the importance of the locus of control. This is defined as the representation of instances which reinforce or inhibit the behavior of a person. Research on this personality trait distinguish and oppose external and internal instances of determination. External ones are situations, powerful others or chance situations. Internal instances are the person's willpower, competencies, desires, pleasures and the satisfaction that he feels. Lefcourt (1981) and Gana (1995) reported that individuals with a representation of external control often have the impression of being subjected to events that they see as being out of their control. However, those with an internal representation of control, feel they have the power to affect their existence. We propose testing the following hypothesis:

H7 : THE RELATIONSHIP BETWEEN THE FEAR OF AGING AND THE ASPIRATIONS TO BE YOUNGER IS STRONGER IN SENIOR WOMEN WHO HAVE AN INTERNAL VS. EXTERNAL LOCUS OF CONTROL

\section{RESEARCH METHODOLOGY}

\section{The choice of measuring tools of subjective age biases and their antecedents}

Most scales used were developed in the USA. In order to adapt them to a French cultural and social context, they have been subjected to cross translations and a validation procedure.

Subjective age biases scores were obtained by computing the discrepancies expressed in years between chronological age and each of the items of the two subjective age scales: cognitive age and desired age. They were developed successively by Barak and Schiffman (1981) and by Barak, Stern and Gould (1988). The uni-dimensional structure of the cognitive age scale has been established on several occasions (Wilkes, 1992; Van Auken and Barry, 1995). It was also used successfully in a French social context (Gana, 1995 ; Guiot, 1999). Adapted from this measure, the scale of desired age is used to measure ideal age-role self-concept (the age that an individual would like to be). The two scales of subjective age were administered at the end of the questionnaire. 
Two scales from Self-Perception Profile by Harter (1990) enabled the measurement of selfesteem and perceived physical attractiveness. They include items whose format was designed to minimize the phenomena of social desirability due to the sensitive nature of this part of the inquiry. These measures were further validated by Martin and Kennedy (1993). The aspiration to be younger was put into operation by adapting a measuring scale for the tendency to social comparison proposed by these authors using Harter's format. It was also justified due to the very marginal proportion of seniors who present an older bias. Only $1.5 \%$ of a pre-tested sample of senior women $(\mathrm{N}=128)$ showed a cognitive older bias (difference between chronological age and cognitive age). However, no senior female questioned showed a desired older bias, which is not surprising.

Items of the degree of feeling of staying young were developed from two sources: articles on the sense of continuity (Mischel, 1969; Kaufman, 1986; Gana, 1995) and the scale of selfconsciousness (Fenigtsein et al., 1975) from which certain questions were adapted. In total, 17 items (Likert in 7 points) were developed after a series of pretests.

Klemmack, Durand and Roff's scale (1980) was used to measure the concept of fear of aging which was defined as the collection of personal preoccupations of an individual towards the consequences of aging.

Alaphilippe and Chasseigne proposed a French version of Rotter's scale (1966) which was validated on seniors. This contained 10 items, 3 were kept after a purification phase.

Finally the scale of concern for physical appearance (Likert in 7 points) was developed from works by Netemeyer et al. (1995). 
TABLE I. - Sample Measurement Items

\section{RATIO SCALES:}

Cognitive age (3 items: $\alpha=0.93$ )

I feel as though I were years old

Desired age (4 items: $\alpha=0.91$ )

I would like to look as though I were years old

\section{LIKERT SCALES:}

Fear of aging (3 items : $\alpha=0.85)$

I feel that people will ignore me when I am old

Feeling of remaining young (3 items : $\alpha=0.73$ )

Even though I'm getting older, I feel as if I'm still young

Concern for physical appearance (4 items : $\alpha=0.72$ )

The way I look is extremely important to me

- Locus of control (3 items : $\alpha=0.73$ )

I'm capable of almost everything if I really want it

SCALES USING HARTER'S FORMAT:

\begin{tabular}{|c|c|l|l|l|l|l|}
\hline $\begin{array}{c}\text { Really } \\
\text { true for } \\
\text { me }\end{array}$ & $\begin{array}{c}\text { Sort of } \\
\text { true for } \\
\text { me }\end{array}$ & \multicolumn{2}{|c|}{ Aspiration to be younger (3 items : $\alpha=0.72)$} & $\begin{array}{c}\text { Sort of } \\
\text { true for } \\
\text { me }\end{array}$ & $\begin{array}{c}\text { Really } \\
\text { true for } \\
\text { me }\end{array}$ \\
\hline & & $\begin{array}{l}\text { Some women do } \\
\text { everything to remain } \\
\text { young }\end{array}$ & BUT & $\begin{array}{l}\text { Other women hardly } \\
\text { care }\end{array}$ & & \\
\hline & \multicolumn{2}{|c|}{ Self esteem (3 items $: \alpha=0.70)$} & & \\
\hline & $\begin{array}{l}\text { Some women like the } \\
\text { kind of person they } \\
\text { are }\end{array}$ & BUT & $\begin{array}{l}\text { Other women often } \\
\text { wish they were } \\
\text { someone else }\end{array}$ & & \\
\hline & Perceived physical appearance (3 items $: \alpha=0.71)$ & & \\
\hline & $\begin{array}{l}\text { Some women are not } \\
\text { happy with the way } \\
\text { they look }\end{array}$ & BUT & $\begin{array}{l}\text { Other women are } \\
\text { happy with the way } \\
\text { they look }\end{array}$ & & \\
\hline
\end{tabular}




\section{Implementation of the final study}

As the main problem is essentially theoretical, the achievement of research goals should be facilitated by recourse to a homogenous sample and by controlling exogenous sources of variance. In order to minimize the influence of differences in regions and living standards on the formation of subjective age biases (Attias-Donfut, 1991), the respondents recruited lived in the same city. This was checked by the postal code which was given at the end of the questionnaire. To this end, a self-administered questionnaire was circulated to a convenience sample of 225 women aged between 50 to 83 years (average age $=62.73$ ) living in Melun (Seine et Marne department). Its composition is given in detail in appendix 1.

\section{RESULTS}

\section{Validation of constructs}

It was necessary to pre-test the scales because certain concepts included here have never been used in France.

Initially, measures of cognitive age and desired age underwent a validation process. ${ }^{1}$. An exploratory analysis of all eight subjective age items on an initial sample $(\mathrm{N}=128)$ let us identify a factorial structure corresponding to the 2 assumed dimensions. The factorial analysis (oblimin rotation) let us restore $82.7 \%$ of the variance, explained with the 2 correlated factors $(r=0.44)$ with eigenvalues higher than 1 and where each of the items strongly load their original factor (loading mean $=0.89$ ). The reliability of cognitive and ideal age scales are satisfactory $(\alpha=0.93$ and $\alpha=0.91$ respectively).

Next, two variables corresponding to cognitive and desired age biases were built by calculating the difference between chronological age and each of the items of the cognitive and desired age scales. The average differences are 11.97 years for cognitive age bias and 20.16 years for the desired age bias. Then, a confirmatory model (EQS 5.7) was established for the final data

1 The item «I look like a person who is __ years old» (LOOK AGE) was eliminated from the statistical analysis. It does not correspond well to the concept of cognitive age which is more an inner belief (Wilkes, 1992; Barak, 1998). A confirmatory factorial analysis confirmed this decision. 
$(\mathrm{N}=225)$. The estimation was carried out by the maximum likelihood method with robust statistics given the non-multinormality of the data (critical Mardia ratio $=41.620$ ). The fit was satisfactory (Satorra-Bentler $\chi^{2}=9.968 ; \quad \mathrm{p}=0.696 ;$ robust $\mathrm{CFI}=1.000 ; \quad \mathrm{AGFI}=0.950$; RMSEA=0.04). Loadings varied from 0.728 to 0.922 with an average of 0.824 . The factors are correlated $(\mathrm{r}=0.51)$.

In a complete model of structural equations, the reliability of the two new variables obtained was estimated by calculating Joreskorg's rho ( $\rho=0.91$ and $\rho=0.93$ respectively). The composite reliability coefficients of the other constructs varied between 0.75 and 0.91 . The convergent and discriminant validities of the constructs were verified using the method proposed by Fornell and Larker (1981). In general, psychometric qualities of measures used proved to be enough. These first results enabled us to empirically test the integral conceptual framework.

\section{The causal model}

The hypotheses were tested using a structural equation model estimated with the help of partial least squares (PLS) estimation. This method is preferred to a classical analysis of covariance structures for several reasons. First the PLS approach is particularly well suited to the basic analysis of heterogeneous data because of the different types of variables (particularly nominals and ordinals) and the measurement formats associated with them. Collecting data relative to subjective age bias (ratio scales), self-esteem (scale using Harter format) and other constructs evaluated using the Likert scales makes the estimation difficult because of the maximum of likelihood properties. This one is based on hypotheses of multinormality and of sufficient sample sizes. Some of the variables showed a non-multinormal distribution (subjective age biases). In addition, the test of a moderating effect of the locus of control required an analysis of two groups of senior women. Those with an internal locus of control and those with an external locus of control. The samples formed were too small for a LISREL type model to be applied without biasing the estimation of the parameters. Several authors have shown that the PLS method correctly manages constraints (Fornell and Bookstein, 1982; Falk and Miller, 1992). 
In order to facilitate the presentation of results, we shall begin by examining the role of the fear of aging in the relation between self-esteem and the aspiration to being younger. Then all causal links of the model are studied.

\section{The mediating effect of the fear of aging on the relationship between self-esteem and the aspiration to be younger in seniors.}

On a theoretical level, the mediating nature of the variable "fear of aging" will be established if the following three conditions are respected (Baron and Kenny, 1986): (1) self-esteem significantly affects the fear of aging (2) self-esteem exercises a significant direct influence on the aspiration to be younger and (3), when the relationship between the fear of aging and the aspiration to be younger is controlled, the intensity of the relationship in the first condition falls. The explanatory capacity of the indirect model obtained increases significantly compared to the direct relation. Each condition was examined and subjected to a PLS model. A bootstrap replication procedure was applied using PLS-Graph software (version 2.91.03.04) which enabled the significance of the relations to be checked (Chin, 1998; 1999). The following table summarizes the results.

Table II - The mediating role of the fear of aging in the relationship between self-esteem and an aspiration to be younger

(1) Effect of self-esteem on the fear of aging: $\mathrm{R}^{2}+=9.8 \%$

$-0.31 *$ self-esteem $=$ fear of aging

$$
(\mathrm{t}=-5.48)
$$

(2) Direct effect of self-esteem on the aspiration to be younger: $\mathrm{R}^{2}=10.8 \%$

$-0.33 *$ self-esteem $=$ aspiration to be younger

$$
(\mathrm{t}=-5.29)
$$

(3) Indirect effect of self-esteem on the aspiration to be younger: $\mathrm{R}^{2}+=15,2 \%$

$-0,26$ * self-esteem $+0.21 *$ fear of aging $=$ aspiration to be younger

$$
(\mathrm{t}=-3,89) \quad(\mathrm{t}=2,86)
$$


Self-esteem has an impact on the fear of aging. It also has a direct influence $(t=-5.29)$ on the aspiration to be younger. However, this effect falls from 0.33 to 0.26 when the fear of aging is included in the model. Simultaneously, the predictive capacity of the model obtained significantly increases according to the results of an increment test $(F=11.52 ; p=0.00)$ using the procedure described by Jaccard, Turrisi and Wan (1990). Introduced into the model, the fear of aging has an indirect effect of $21.2 \%(0.33-0.26 / 0.33)$ between self-esteem on the aspiration to be younger. It is a partial mediator in this relationship. This is stronger when individuals are very scared of getting older. If the direct link is significant, the impact on other variables should be identified that are likely to affect this relation. This leads us to examine the nature of the influence of locus of control.

\section{Locus of control: a moderating variable of the relation between fear of aging and}

\section{aspiration to be younger}

We postulated there would be a stronger link in persons with internal locus of control than those with external locus of control. Unfortunately PLS-Graph software does not directly enable several groups to be analysed. However, it automatically provides correlations between latent variables. This possibility facilitates the comparison of the intensity of effects on two independent samples with the help of a difference of correlations test. In order to test the hypothesis of the moderating role of the control representation, we split the seniors' sample in two, at the median of the control representation variable. Then on each group we carried out a difference of correlation test ${ }^{1}$ between the fear of aging and the aspiration to be younger (table III).

\footnotetext{
${ }^{1}$ The results of this procedure are similar to those obtained by the method of multi-group analysis developed by Keil et
} al. (1999) and recommended by Chin. It is a technique which is compatible with PLS. 
Tableau III - The moderating role of locus of control

\begin{tabular}{l}
\begin{tabular}{|c|c|c|c|}
\hline Locus of control & $\mathbf{N}$ & $\mathbf{R}$ & Significance \\
\hline Internal & 113 & $\begin{array}{c}0.35^{* *} \\
(\mathrm{p}=0.00)\end{array}$ & $\mathrm{p}=0.05$ \\
\hline External & $11 \mathrm{e}$ & $\begin{array}{c}0.15^{\mathrm{NS}} \\
(\mathrm{p}=0.12)\end{array}$ & \\
\hline ** significant at 0.01 & NS non significant
\end{tabular} \\
\hline
\end{tabular}

Although the coefficients are relatively low, the results show that the relation between the fear of aging and the aspiration to be younger is only significant for "internal" persons. These people have a higher feeling of control over events in their life. They are more inclined to react when faced with signs of aging.

Thus hypotheses H6 and H7 are validated.

\section{The causal model}

The hypotheses were tested using a PLS approach with a bootstrap simulation. The results of the structural model are presented in figure I.

On the whole, the relations tested were significant (table IV). The intensity of the link between perceived physical appearance and self-esteem was modest with $14.6 \%$ explained variance. Hypothesis H3 is supported for seniors. 
Table IV - The estimation of parameters of the causal model by the bootstrap method:

Determinants of subjective age bias in women seniors

\begin{tabular}{|c|c|c|c|c|c|c|}
\hline \multicolumn{2}{|r|}{ Results of hypothèses } & $\begin{array}{l}\text { B1 Para- } \\
\text { meter }\end{array}$ & $\begin{array}{l}\text { B2 Para- } \\
\text { meter }\end{array}$ & $\begin{array}{l}\text { Standar } \\
\text { deviation }\end{array}$ & t Test & sig \\
\hline $\mathrm{H} 2 \mathrm{~b}$ & $\begin{array}{r}\text { Aspiration to be younger } \rightarrow \text { Cognitive age bias } \\
\text { REJECTED }\end{array}$ & 0.15 & 0.13 & 0.09 & 1.69 & 0.09 \\
\hline $\mathrm{H} 1 \mathrm{~b}$ & $\begin{array}{ll}\text { Aspiration to be younger } \rightarrow \text { Desired age bias } \\
\text { VALIDATED }\end{array}$ & 0.23 & 0.24 & 0.06 & 3.85 & 0.00 \\
\hline H3 & $\begin{aligned}: \text { Perceived physical appearance } \rightarrow \text { Self-esteem } \\
\text { VALIDATED }\end{aligned}$ & 0.38 & 0.39 & 0.07 & 5.61 & 0.00 \\
\hline H5 & $\begin{array}{l}\text { Concern for physical appearance } \\
\rightarrow \text { Aspiration to be younger }\end{array}$ & 0.13 & 0.15 & 0.07 & 1.83 & 0.07 \\
\hline H6 & Self-esteem $\rightarrow$ Fear of aging & -0.31 & -0.31 & 0.07 & -4.68 & 0.00 \\
\hline & $\begin{array}{l}\text { Aspiration } \\
\text { to be younger }\end{array}$ & 0.19 & 0.19 & 0.07 & 2.59 & 0.01 \\
\hline & $\begin{array}{c}\text { Aspiration to be younger } \\
\text { VALIDATED }\end{array}$ & -0.27 & -0.27 & 0.07 & -3.65 & 0.00 \\
\hline $\mathrm{H} 4$ & $\begin{aligned} & \text { Perceived physical appearance } \rightarrow \text { Feeling of } \\
& \text { staying young } \\
& \text { VALIDATED }\end{aligned}$ & 0.36 & 0.37 & 0.06 & 5.92 & 0.00 \\
\hline $\mathrm{H} 2 \mathrm{a}$ & : Feeling of staying young $\rightarrow$ Cognitive age bias & 0.29 & 0.30 & 0.06 & 4.83 & 0.00 \\
\hline $\mathrm{H} 2 \mathrm{~b}$ & $\begin{array}{r}\text { Feeling of staying young } \rightarrow \text { Desired age bias } \\
\text { REJECTED }\end{array}$ & 0.02 & 0.02 & 0.08 & 0.03 & 0.98 \\
\hline
\end{tabular}

B1: Parameter from total sample

B2 : Average parameters from bootstrap simulations 
FIGURE I - The antecedents of subjective age biases ${ }^{1}$

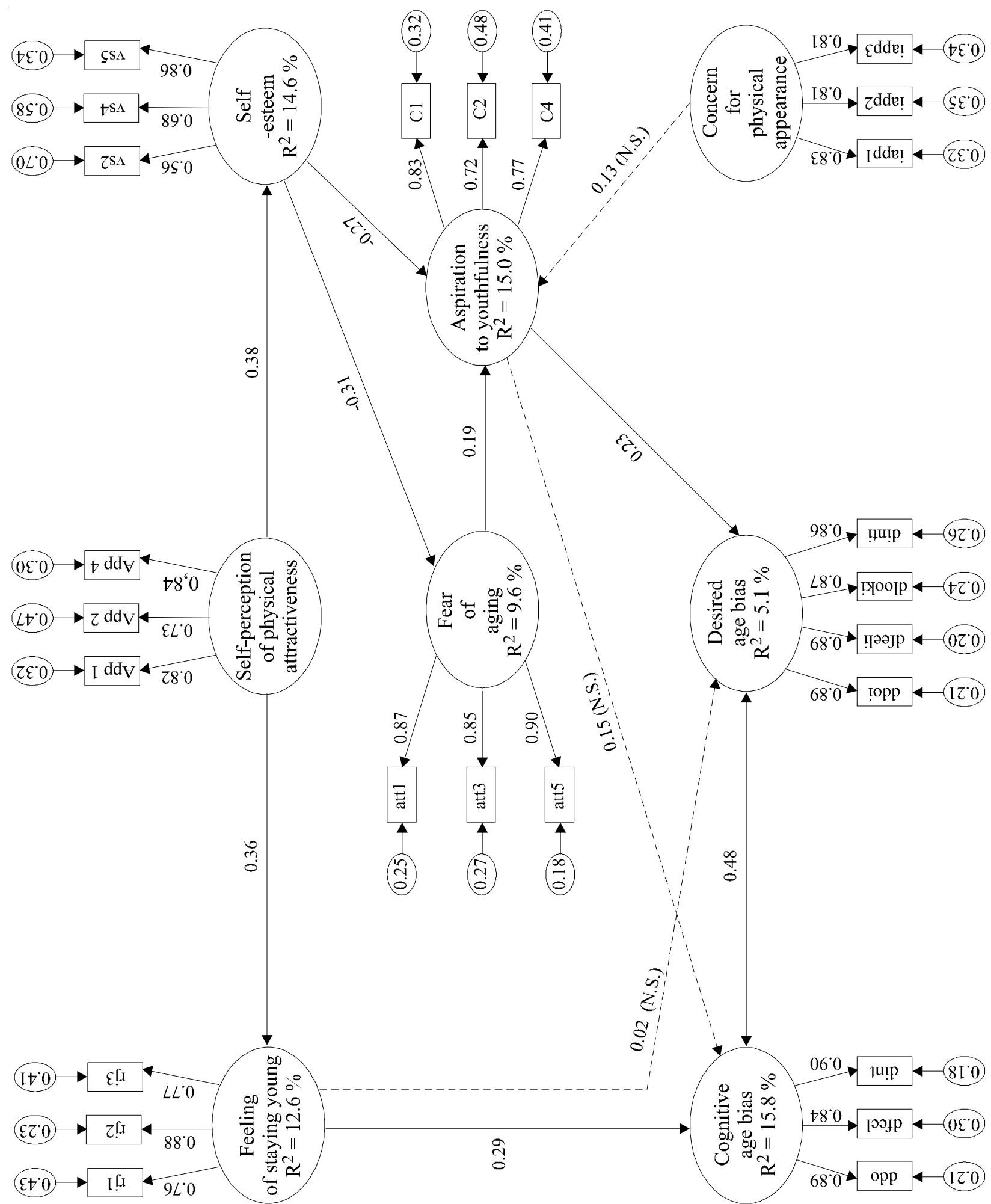

\footnotetext{
${ }^{1}$ In the measurement model, figures correspond to loadings and residual variances
} 
Aspiration to be younger in seniors is influenced by low self-esteem and fear of aging. However the relation between concern for physical appearance and aspiration to be younger is not very significant $(B=0.13 ; \mathrm{p}=0.07)$.

The structure of the model founded on hypotheses H5 and H6 enables $15.0 \%$ of the variance of the aspiration to be younger to be reconstituted.

The feeling of remaining young is only linked to the cognitive age bias $(B=0.29 ; t=4.83 ; \mathrm{p}=$ 0.00). It explains $15.8 \%$ of the variance. Hypothesis $\mathrm{H} 2$ is therefore validated. However, the relation between this variable and the desired age bias variable is not significant.

The feeling of remaining young seems to be one of the antecedent variables of cognitive age bias. Based on the theory of continuity, it seems to be induced by perceived physical appearance $(\mathrm{B}=0.36)$ with $12.6 \%$ of explained variance (hypothesis H4). The influence of the aspiration to be younger is very low on the desired age bias (5.1\% of explained variance). It appears that the cognitive age bias is more forceful for women over fifty.

In order to identify groups of senior women characterized by subjective age biases a cluster analysis was carryied out.

\section{PROFILES OF SENIOR WOMEN ACCORDING TO THEIR SUBJECTIVE AGE BIASES}

Individual latent variable scores taken from the PLS model were clustered using Ward's method. A dendrogramm revealed a division into 4 classes of individuals in groups of approximately the same size. An initial discriminant analysis enables individuals to be placed in the clusters determined in the preceding stage. The results (lambda of Wilks $=0.12 ; \mathrm{F}=$ $138.00 ; \mathrm{p}=0.00)$ validates the profile carried out on active variables with a good percentage of classification of $95.1 \%$.

Typology analysis is important to determine group profiles of seniors from subjective age biases and their determinants. To this end, the determinants were first introduced with 
chronological age as explanatory variables in a second discriminant analysis of groups obtained from the cluster analysis (lambda of Wilks $=0.665 ; \mathrm{F}=8.01 ; \mathrm{p}=0.00$ )

Four determinants explain where individuals are classed, the clusters defined in terms of subjective age bias: the aspiration to be younger, concern for physical appearance, the locus of control and self-esteem. The correct classification percentage is $47.1 \%$ with 4 clusters. Although quite low, the result is not insufficient. It is linked to poorer prediction in one cluster compared to the others (cluster 3, with $26.7 \%$ of individuals classed correctly). This is not due to hazard, because in this case the classification percentage was only approximately $25 \%$. A graph showing the averages of variables of each cluster enables their profile to be determined (figure II).

FIGURE II - Profiles of women seniors obtained from hierarchical cluster analysis

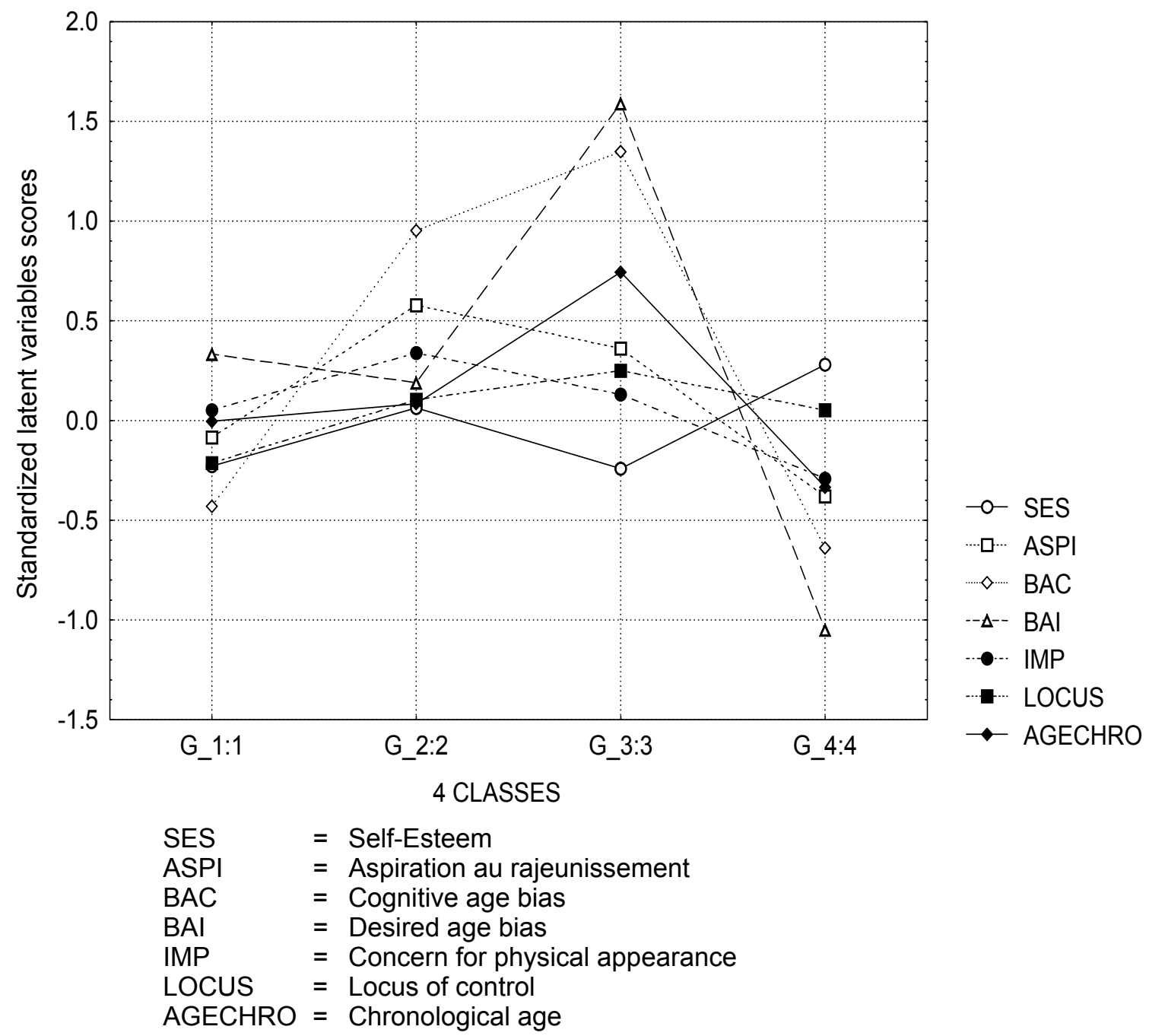


Clusters 3 and 4 have radically opposing profiles. With $13.3 \%$ of numbers, cluster 3 is characterized by average age seniors (in their sixties) with a high subjective age bias on both dimensions, an average desire to be younger, rather negative self-esteem and an internal locus of control. Cluster 4 is large. It accounts for $34.2 \%$ of the sample. It unites women in their fifties with low subjective age biases. These individuals have relatively low concern for physical appearance. Their self-esteem is on the positive side and they manifest only a low desire to be younger.

With a third of individuals, category 1 has a profile similar to category 4 . The main differences are that it has an average desired age bias and lower self-esteem.

Finally, $19.1 \%$ of senior women make up cluster 2 . These have an average chronological age (62.3 years), they manifest a desire to become younger and place great concern for physical appearance. Their cognitive age bias is rather high whilst their desired age bias is average. This group along with cluster 3 could form the most interesting target for marketing anti-aging products or other products designed to increase youthfulness. Such products meet compensatory expectations and/or consolidate tendencies of younger self-perception. The potential of the two categories is $31.4 \%$ in our sample.

This classification was carried out for descriptive and operational purposes. It validates a large part of the PLS model. The results further underline the interest of the aspiration to younger variable for segmenting and targeting prospects.

\section{CONCLUSION}

From the theory of social comparison, subjective age biases were seen as the effects of developmental aspirations.

The results from seniors show that the cognitive age bias seems more to result from a feeling of remaining young than an aspiration to be younger. This observation underlines the interest of the theory of continuity to explain the formation of subjective age biases in seniors. It reveals feelings of permanence and stability of individuals over 50 despite physical and social changes confronting them. 
In the framework of a multivariate approach, contrasting most other studies, other determinants were identified. Concern for physical appearance and self-esteem are linked to developmental aspirations. The latter particularly affect the desired age bias. Seen as manifestations of selfimage defense mechanisms, the desired age bias is more likely to be activated when self-esteem is negative.

Moreover, relations established with elements of physical self (appearance) show their importance in the formation of youthful biases.

The causal model identified determinants of subjective age biases. Large individual differences may be revealed on these variables. Combining them enables different groups of seniors to be characterized according to the degree of cognitive and desired age biases. For the over fifties, the breakdown obtained could be used as targets for marketing anti-aging products. Women over fifty show distinct attitudes towards aging and have varied expectations in terms of consuming anti-aging products. The possibilities of market segmentation should be similar to the groups defined above. They are the starting point for marketing operations as they propose a targeting tool. Such a tool is based on the elaboration of typologies of subjective age biases prepared using their antecedent variables. These typologies may be considered as a partial response to strategic and operational imperatives of companies specialized in the marketing of cosmetic companies such as, for example Beiersdorf (Nivea Vital) (Allérès, 1986). They are also of interest to individuals in other age brackets. Indeed, according to managerial journals, anti-aging products are used at an increasingly young age. Typologies could find a wider application to include all anti-age products, not just anti-aging treatments. Such products include many personal hygiene products.

The limits of this research must also be presented. First, the existence of these antecedent variables must be verified on a more representative sample of senior French females. Moreover, other variables must be integrated in order to fine-tune the typologies presented. This would improve the possibilities of market segmentation. Thus a more in-depth study of antecedent variables should be carried out in order to improve the prospecting or even the loyalty of segments most susceptible to manifest subjective age biases. 


\section{REFERENCES}

Alaphilippe D. and Bailly N. (1997), Evolution de la représentation de soi chez les personnes âgées, Psychologie Française, 42, 4, 355-364.

Atchley R.C. (1993), A Continuity Theory of Normal Aging, The Gerontologist, 29, 183-190.

Atchley R.C. (1996), Continuity Theory and the Evolution of Activity in Later Adulthood, Activity and Aging, ed. J.R. Kelly, Newbury Park, California, Sage Publications, 1-16.

Attias-Donfut C. (1991), Générations et âges de la vie, Paris, Presses Universitaires de France.

Barak B. (1998), Inner-Ages of Middle-Aged Prime-Lifers, International Journal of Aging and Human Development, 46, 3, 189-228.

Barak B. and Schiffman L.G. (1981), Cognitive Age: A Non-Chronological Age Variable, Advances in Consumer Research, 8, ed. K. Monroe, Ann Arbor, Michigan, Association for Consumer Research, 602-606.

Barak B. and Stern B.B. (1985), Women's Age in Advertising: An Examination of Two Age Profiles, Journal of Advertising Research, 25, 38-47.

Barak B. and Stern B.B. (1986), Subjective Age Correlates : A Research Note, The Gerontologist, 26, 5, 571-578.

Barak B., Stern B.B. and Gould S.J. (1988), Ideal Age Concepts: An Exploration, Advances in Consumer Research, 15, ed. M. Houston, Ann Arbor, Michigan, Association

Baron R.M. and Kenny D.A. (1986), The Moderator-Mediator Variable Distinction in Social Psychological Research: Conceptual, Strategic and Statistical Considerations, Journal of Personality and Social Psychology, 51, 6, 1173-1182.

Blau Z.S. (1956), Changes in Status and Age Identification, American Sociological Review, 21, 198-203.

Brandtstädter J. (1989), Personal Self Regulation, Developmental Psychology, 25, 96-108.

Chin W.W. (1998), The Partial Least Squares Approach for Structural Equation Modeling, Modern Methods for Business Research, ed. G.A. Marcoulides, Londres, Lawrence Erlbaum Associates, 295-336.

Chin W.W. and Newsted P.R. (1999), Structural Equation Modeling Analysis with Small Samples Using Partial Least Squares, Statistical Strategies for Small Sample Research, ed. R. Hoyle, Londres, Sage Publications, 307-341.

Chua C., Cote J.A. and Leong S.M. (1990), The Antecedents of Cognitive Age, Advances in Consumer Research, 17, ed. M. Goldberg, G. Gorn and R. Pollay, Provo, Utah, Association for Consumer Research, 880-885.

Engel J.F., Blackwell R.D. and Miniard P.W. (1995), Consumer Behavior, $7^{\text {ième }}$ édition, The Dryden Press.

Eagly A.H., Ashmore R., Makhijani M.G. and Longo L.C. (1991), What Is Beautiful Is Good, But ...: A Meta-Analytic Review of Research on the Physical Attractiveness Stereotype, Psychological Bulletin, 110, 1, 109-128.

Engel J.F., Blackwell R.D. and Miniard P.W. (1995), Consumer Behavior, $7^{\text {ième }}$ édition, The Dryden Press.

Erikson E.H.(1969), Identity: Youth and Crisis, New-York, Norton.

Falk R. and Miller N.B. (1992), A Primer for Soft Modeling, Akron, Ohio, The University of Akron Press.

Fenigstein A., Scheier M.F. and Buss A.H. (1975), Public and Private Self-Consciousness: Assessment and Theory, Journal of Consulting and Clinical Psychology, 43, 522-527.

Festinger L. (1954), A Theory of Social Comparison Processes, Human Relations, 7, 117-140.

Fornell C. and Bookstein F.L. (1982), Two Structural Equation Models: LISREL and PLS applied to Consumer Exit-Voice Theory, Journal of Marketing Research, 19, 11, 440-452.

Fornell C. and Larcker D.F. (1981), Evaluating Structural Equation Models with Unobservable Variables and Measurement Errors, Journal of Marketing Research, 18, 2, 39-50. 
Franzoi S.L. (1995), The Body as Object Versus the Body as Process: Gender Differences in the Experience of Body Awareness: An Experiential Sampling Study, Sex Roles, 21, 10, 499515.

Gana K. (1995), Concept de soi et vieillissement, thèse de doctorat en psychologie, Université François Rabelais, Tours.

Guiot D. (1999), Age subjectif et segmentation des seniors, Décisions Marketing, 18, Septembre-Décembre, 15-23.

Harter S. (1990), Manual for the Self-Perception Profile for Adults, Denver, Colorado, University of Denver.

Hagestad G.O. and Neugarten B.L. (1985), Age and the Life Course, Handbook of Aging and the Social Sciences, ed. R.H. Binstock and E. Shanas, New-York, Van Nostrand Reinhold, 3561.

Hansson R.O. (1989), Old Age: Testing the Parameters of Social Psychological Assumptions, The Social Psychology of Aging, ed. Spacapam and S. Oskamp, Newbury Park, California, Sage Publications, 25-51.

Heckhausen J. and Krueger J. (1993), Developmental Expectations for the Self and Most Other People: Age Grading in Three Functions of Social Comparison, Developmental Psychology, 29, 3, 539-548.

Heckhausen J. and Schulz R. (1995), A Life-Span Theory of Control, Psychological Review, 102, 284-304.

Henderson K.V., Goldsmith R.E. and Flynn L.R. (1995), Demographic Characteristics of Subjective Age, Journal of Social Psychology, 135, 4, 447-457.

Higgins E.T. (1987), Self-Discrepancy: A Theory Relating Self and Affect, Psychological Review, 94, 319-340.

Hubley A.M. and Hultsch D.F. (1994), The Relationship of Personality Trait Variables to Subjective Age Identity in Older Adults, Research on Aging, 16, 4, 415-439.

Jaccard J., Turrisi R. and Wan C.K. (1990), Interaction Effects in Multiple Regression, Sage University Paper, Series on Quantitative Applications in the Social Sciences, 92, Newbury Park, California, Sage.

Johnson E.B. (1995), Cognitive Age: Understanding Consumer Alienation in the Mature Market, Review of Business, 17, 3, 35-40.

Kaufman S.R. (1986), The Ageless Self Sources of Meaning in Late Life, Madison, Wisconsin, University of Wisconsin Press.

Kastenbaum R., Derbin V., Sabatini P. and Arrt S. (1972), The Ages of Me Toward Personal and Interpersonal Definitions of Functional Aging, Aging and Human Development, 3, 1, 197 211.

Keil M.,Tan B.C.Y., Wei K-F., Saarinen T., Tuunainen V. and Wassenaar (2000), A CrossCultural Study on Escalation of Commitment Behavior in Software Projects, MIS Quaterly, june (forthcoming).

Krantz M., Friedberg J. and Andrews D. (1985), Physical Attractiveness and Popularity: The Mediating Role of Self Perception, The Journal of Psychology, 119, 3, 219-223.

Lefcourt H.M. (1981), Research With the Locus of Control Construct Vol. 1: Assessment Methods, New York, Academic Press.

Martin M.C. and Kennedy P.F. (1993), Advertising and Social Comparison : Consequences for Female Preadolescents and Adolescents, Journal of Marketing, 10, 6, 513-530.

Mischel W. (1969), Continuity and Change in Personality, American Psychologist, 24, $1012-$ 1018.

Montepare J. M. and Lachman B. (1992), You Are Only Old As You Feel, Psychology and Aging, 4, 73-78.

Moschis G.P. (1992), Marketing to Older Consumers, Westport, Connecticut, Quorum Books. 
Netemeyer R.G., Burton S. and Lichtenstein D.R. (1995), Trait Aspects of Vanity: Measurement and Relevance to Consumer Behavior, Journal of Consumer Research, 21, 3, 612-626.

Neugarten B.L. (1968), The Awareness of Middle Age, Middle Age and Aging, a Reactor in Social Psychology, ed. B.L. Neugarten, The University of Chicago Press, 211-216.

Neugarten B.L. (1979), Time, Age and the Life Cycle, The American Journal of Psychiatry, 7, 887-894.

Richins M.L. (1991), Social Comparison and the Idealized Images of Advertising, Journal of Consumer Research, 18, 6, 71-83.

Rozin P. and Fallon E. (1988), Body Image, Attitudes to Weight and Misperceptions of Figure Preferences of the Opposite Sex: A Comparison of Men and Women in Two Generations, Journal of Abnormal Psychology, 97, 8, 342-345.

Staats S. (1996), Youthful and Older Biases as Special Cases of A Self Age Optimization Bias, International Journal of Aging and Human Development, 43, 4, 267-276.

Steitz J.A. and McClary A.M. (1988), Subjective Age, Age Identity, and Middle-Age Adults, Experimental Aging Research, 14, 2, 83-88.

Stephens N. (1991), Cognitive Age: A Useful Concept for Advertising?, Journal of Advertising, 20, 4, 37-47.

Tepper K. (1994), The Role of Labeling Processes in Elderly Consumers' Responses to Age Segmentation Cues, Journal of Consumer Research, 20, 3, 503-519.

Sontag S. (1975), The Double Standard of Aging, No Longer Young: The Older Woman in America, Occasional Papers in Gerontology, 11, Institute of Gerontology, University of Michigan - Wayne State University, Ann Arbor, Michigan.

Thomae H. (1970), Theory of Aging and Cognitive Theory of Personality, Human Development, 13, 1-16.

Van Auken S. and Barry T.E. (1995), An Assessment of the Trait Validity of Cognitive Age Measures, Journal of Consumer Psychology, 4, 2, 107-132.

Vacker B. and Key W.R. (1993), Beauty And The Beholder: The Pursuit of Beauty Through Commodities, Psychology and Marketing, 10, 6, 471-494.

Wilkes, R.E. (1992), A Structural Modelling Approach to the Measurement and Meaning of Cognitive Age, Journal of Consumer Research, 19, 9, 292-301.

Wolfe D.B. (1990), Serving the Ageless Market: Strategies for Selling to the Fifty-Plus Market, New York, McGraw-Hill. 
Appendix I - Description of the sample of the final survey $(N=225)$

\begin{tabular}{|c|c|c|c|c|c|c|}
\hline \multicolumn{7}{|l|}{ Age } \\
\hline & & \multicolumn{3}{|l|}{ Average } & \multicolumn{2}{|l|}{62.7} \\
\hline & & \multicolumn{2}{|c|}{ Minimum - Maximum } & & \multicolumn{2}{|l|}{$50-83$} \\
\hline & & \multicolumn{3}{|l|}{ Standard deviation } & \multicolumn{2}{|l|}{10.2} \\
\hline \multicolumn{7}{|c|}{ Status marital } \\
\hline & & \multicolumn{3}{|l|}{ Single } & 2 & $(0.9 \%)$ \\
\hline & & \multicolumn{3}{|c|}{ Married or living in couple } & 136 & $(60.4 \%)$ \\
\hline & & \multicolumn{3}{|l|}{ Widowed } & 44 & $(19.6 \%)$ \\
\hline & & \multicolumn{3}{|c|}{ Separated or divorced } & 35 & $(15.5 \%)$ \\
\hline & & \multicolumn{3}{|l|}{ No reply } & 8 & $(3.6 \%)$ \\
\hline \multicolumn{7}{|c|}{ Professional status } \\
\hline & \multirow{2}{*}{\multicolumn{4}{|c|}{$\begin{array}{l}\text { Active } \\
\text { breakdown }\end{array}$}} & \multirow{8}{*}{\multicolumn{2}{|c|}{$101(44.9 \%)$}} \\
\hline & & & & & & \\
\hline & & Unskilled worker & 4 & $(4.0 \%)$ & & \\
\hline & & Employee & 34 & $(33.7 \%)$ & & \\
\hline & & Middle manager & 19 & $(18.8 \%)$ & & \\
\hline & & Upper manager & 5 & $(4.9 \%)$ & & \\
\hline & & Self-employed & 8 & $(7.9 \%)$ & & \\
\hline & & Other & 31 & $(30.7 \%)$ & & \\
\hline & Retired & & & & 113 & $(50.2 \%)$ \\
\hline & No reply & & & & 11 & $(4.9 \%)$ \\
\hline
\end{tabular}

